\title{
Effects of ferric salt of different forms on phosphorus removal
}

\author{
Jingliang Xie ${ }^{1, *}$, Anran Peng ${ }^{1}$, Qiang Wang ${ }^{2}$, Yuan jie Sun ${ }^{1}$ \\ ${ }^{1}$ School of Enviromental and Municipal Engineering, Qingdao University of Technology, Qingdao 266033, China \\ 2Qingdao Shuang Yuan Water Affairs Co., Ltd., Qingdao 266109, China \\ Received: 06/07/2020, Accepted: 06/08/2020, Available online: 22/10/2020 \\ *to whom all correspondence should be addressed: e-mail: jingliangx@163.com \\ https://doi.org/10.30955/gnj.003409
}

\section{Graphical abstract}

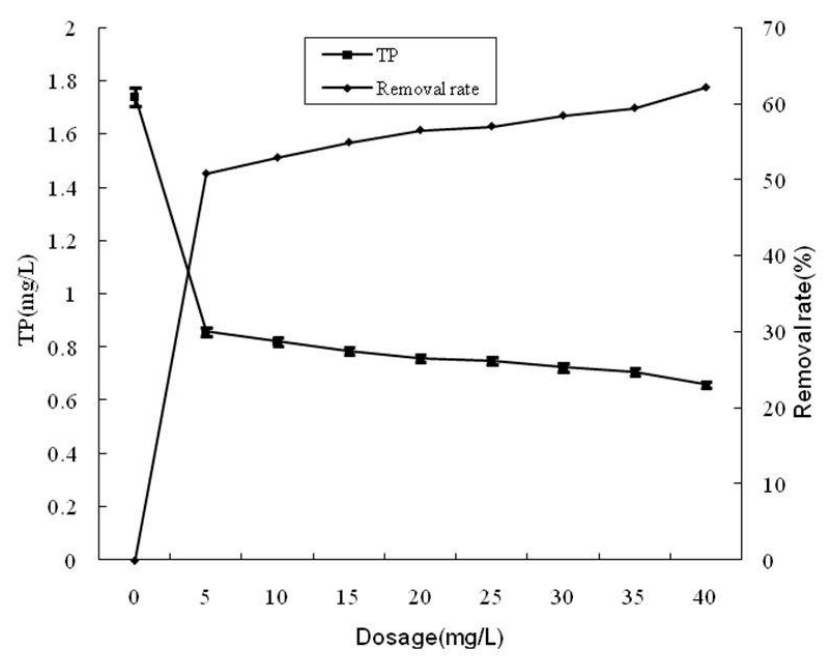

\section{Abstract}

This paper has studied phosphorus removal effects of ferric chloride (ionic state), polyferric chloride (polymer state) and ferric hydroxide (gel state) on the effluent of a municipal sewage treatment plant. The total phosphorus (TP) in the effluent was $1.74 \mathrm{mg} \cdot \mathrm{L}^{-1}$. Results showed that ferric chloride was the best phosphorus remover among the three forms of ferric salt coagulants. With a dosage of $40 \mathrm{mg} \cdot \mathrm{L}^{-1}$, its phosphorus removal rate could reach $90 \%$ and TP in the treated wastewater was reduced to less than 0.17 $\mathrm{mg} \cdot \mathrm{L}^{-1}$. After the treatment, the effluent quality met the first level A criteria in the Discharge Standard of Pollutants for Municipal Wastewater Treatment Plant (GB189182002). At the same doage of $40 \mathrm{mg} \cdot \mathrm{L}^{-1}$, the phosphorus removal rates of polyferric chloride and ferric hydroxide were $62 \%$ and $59 \%$, respectively, lower than the rate of ferric chloride.

Keywords: Municipal wastewater, coagulant, ionic Fe, polymeric $\mathrm{Fe}$, gel $\mathrm{Fe}$, chemical phosphorus removal.

\section{Introduction}

Large-scale Enteromorpha sp. green tides have broken out for several consecutive years in the Yellow Sea of China. This has exposed fragile ecosystems to an ever-increasing risk and affected the tourism of coastal cities. According to the enclosure experiment. (Wu et al., 2010; Zulkapli et al., 2018) in Qingdao offshore, rich nutrients in the estuary area and coastal waters are one of the preconditions for the large-scale propagation and outbreak of enteromorpha prolifera. Phosphorus is the primary limiting nutrient for algae production. The yield of algae can be increased when phosphorus is efficiently utilized from the growth medium (Wang and Peng, 2009). Therefore, controlling phosphorous discharged from municipal wastewater treatment plants is a key factor in preventing eutrophication of surface waters (Luo et al., 2010; Peng and Chen, 1988; Wang et al., 2018; Xiong et al., 2006; Zhang et al., 2019).

Phosphates can be removed from wastewater based on principles of both biology and chemistry. Biological phosphorus removal has poor stability and flexibility (Jin et al., 2002, 2008; Zhang and Peng, 2011), often depending on the quality of influent water and operating conditions, such as carbon source and $\mathrm{pH}$ value (Chen et al., 2004; Liu et al., 2007; Wang et al., 2017; Zhang et al., 2019). The phosphorus content of effluent treated by the biological method often fails to meet national emission standards. $\mathrm{A} / \mathrm{O}, \mathrm{A}^{2} / \mathrm{O}$, Bardenpho and SBR are enhanced biological phosphorus removal processes. When such processes are used to treat municipal wastewater, the phosphorus removal rate could reach $75 \%$ (Deng and Guo, 2002; Niu, 2006; Tian, 1996). In other words, if the TP content of the inlet water is $4-8 \mathrm{mg} / \mathrm{L}$, the TP content of the outlet water will be $1-2 \mathrm{mg} / \mathrm{L}$, which means that the first level A criteria (TP $\leq 0.5 \mathrm{mg} / \mathrm{L}$ ) in the Discharge Standard of Pollutants for Municipal Wastewater Treatment Plant (GB18918-2002) cannot be achieved. Therefore, it is recommended to adopt the chemical phosphorus removal method to improve stability and reach the effluent standard.

In practical engineering, sedimentation, synchronous sedimentation and post sedimentation or flocculation filtration after biological treatment are commonly used for chemical phosphorus removal. They are different in dosing location of the agent. Synchronous sedimentation has nearly $50 \%$ market share, because it does not involve much construction work and has very good settling properties of the sludge. However, in its application to a Qingdao sewage 
treatment plant, the ammonia nitrogen is not up to the standard because the free acid in ferric chloride reduces the alkalinity of sewage and thus affects the nitrification of sludge (Hosseini et al., 2019; Islam et al., 2020; Liu et al., 2003; Parfitt et al., 1975). The following measures can be considered to reduce the influence of free acid: 1 . adding alkali to ferric chloride solution to make polymeric ferric chloride; 2 . adding alkali to ferric chloride solution to directly make ferric hydroxide; 3 . adding ferric chloride to sewage before adding alkali to boost its alkalinity. It is know that various polymerization forms of aluminum chloride show good phosphorus removal effects (Kang and Yang, 2008; Liu et al., 2011; Yang et al., 2009, 2017). However, few reports focus on the phosphorus removal effects of ferric chloride in different polymerization forms.

This paper discussed the phosphorus removal effects of three different polymerization forms of ferri. It aims to provide practical guidance for the engineering application of ferric salts.

\section{Materials and methods}

\subsection{Materials and instruments}

Experimental water: secondary effluent from a Qingdao sewage plant (TP $1.74 \mathrm{mg} / \mathrm{l}, \mathrm{COD}_{\mathrm{cr}} 45 \mathrm{mg} / \mathrm{L}$, ammonia nitrogen $4.5 \mathrm{mg} / \mathrm{l}$, alkalinity $65 \mathrm{mg} / \mathrm{L}$ ).

Chemicals \& Reagents: ferric chloride with analytical purity, and ferric chloride solution with concentration of $10 \%$; alkali was added to $10 \%$ ferric chloride solution to prepare polyferric chloride $(\mathrm{pH}=3.5)$; alkali was added to $10 \%$ ferric chloride solution to prepare ferric hydroxide $(\mathrm{pH}=7)$.

Instruments: Shimadzu UV-mini1240 UV visible spectrophotometer, ZR4-6 mixer, and PHS-3CpH meter, etc.

\subsection{Experimental methods}

First, containers of the mixer were added equal amount of secondary effluent that flowed out of a sewage treatment plant. Second, ferric chloride, polymeric ferric chloride and ferric hydroxide, each with 9 gradients of dosages -0 $\mathrm{mg} / \mathrm{L}, 5 \mathrm{mg} / \mathrm{L}, 10 \mathrm{mg} / \mathrm{L}, 15 \mathrm{mg} / \mathrm{L}, 20 \mathrm{mg} / \mathrm{L}, 25 \mathrm{mg} / \mathrm{L}, 30$ $\mathrm{mg} / \mathrm{L}, 35 \mathrm{mg} / \mathrm{L}$ and $40 \mathrm{mg} / \mathrm{L}$ (all calculated by ferric chloride) - were put into their respective containers.

The coagulation and mixing parameters of the six-joint stirrer were set as follws: 1 ) rapid mixing for $30 \mathrm{~s}$ with speed of $250 \mathrm{r} / \mathrm{min}$; 2) slow mixing for $10 \mathrm{~min}$ with speed of 120 r/min); 3) After standing sedimentation for $30 \mathrm{~min}$, the supernatant was taken to determine the TP.

\section{Results and analysis}

\subsection{Phosphorus removal effects of ionic Fe (ferric chloride)}

Figure 1 shows the TP removal effect of ionic Fe in the secondary effluent when its dosage was $0 \mathrm{mg} / \mathrm{L}, 5 \mathrm{mg} / \mathrm{L}, 10$ $\mathrm{mg} / \mathrm{L}, 15 \mathrm{mg} / \mathrm{L}, 20 \mathrm{mg} / \mathrm{L}, 25 \mathrm{mg} / \mathrm{L}, 30 \mathrm{mg} / \mathrm{L}, 35 \mathrm{mg} / \mathrm{L}$ and 40 $\mathrm{mg} / \mathrm{L}$.

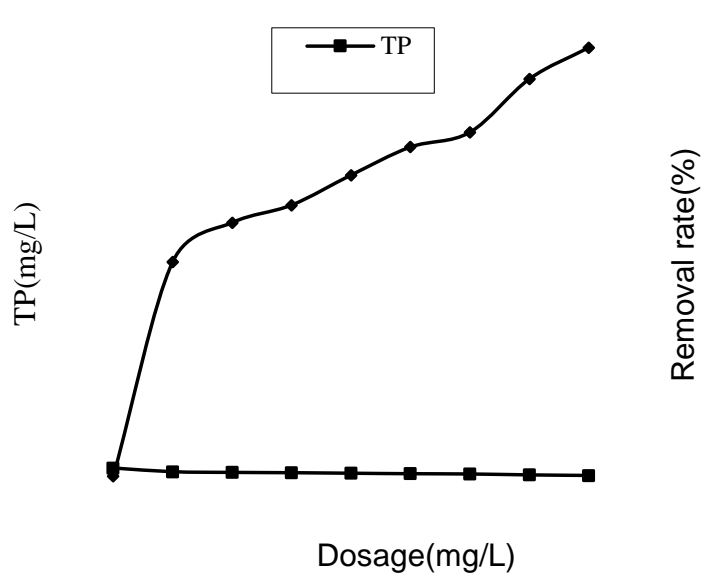

Figure 1. The TP removal effect of ferric chloride with dosages in the secondary effluent

According to Figure 1 , as the dosage of ionic $\mathrm{FeCl}_{3}$ increased, the TP removal rate in the secondary effluent gradually went up. The dosage had a linear correlation with the TP removal rate, with a slope of approximately 0.36 . When the dosage of ionic Fe increased to $40 \mathrm{mg} / \mathrm{L}$, the removal rate of TP grew to $90 \%$, and the TP concentration decreased from $1.74 \mathrm{mg} / \mathrm{L}$ to $0.17 \mathrm{mg} / \mathrm{L}$. After the treatment, TP concentration in the supernatant reached the first level A criteria (TP $\leq 0.5 \mathrm{mg} / \mathrm{L}$ ) in the Discharge Standard of Pollutants for Municipal Wastewater Treatment Plant (GB18918-2002). The additions of ionic Fe kept reducing TP concentration in the supernatant and the declining trend continued.

\subsection{Phosphorus removal effect of polymeric Fe (polyferric chloride)}

Polymeric Fe was added to the secondary effluent. Its removal effect on TP in secondary effluent is shown in Figure 2. The dosages were $0 \mathrm{mg} / \mathrm{L}, 5 \mathrm{mg} / \mathrm{L}, 10 \mathrm{mg} / \mathrm{L}, 15$ $\mathrm{mg} / \mathrm{L}, 20 \mathrm{mg} / \mathrm{L}, 25 \mathrm{mg} / \mathrm{L}, 30 \mathrm{mg} / \mathrm{L}, 35 \mathrm{mg} / \mathrm{L}$ and $40 \mathrm{mg} / \mathrm{L}$.

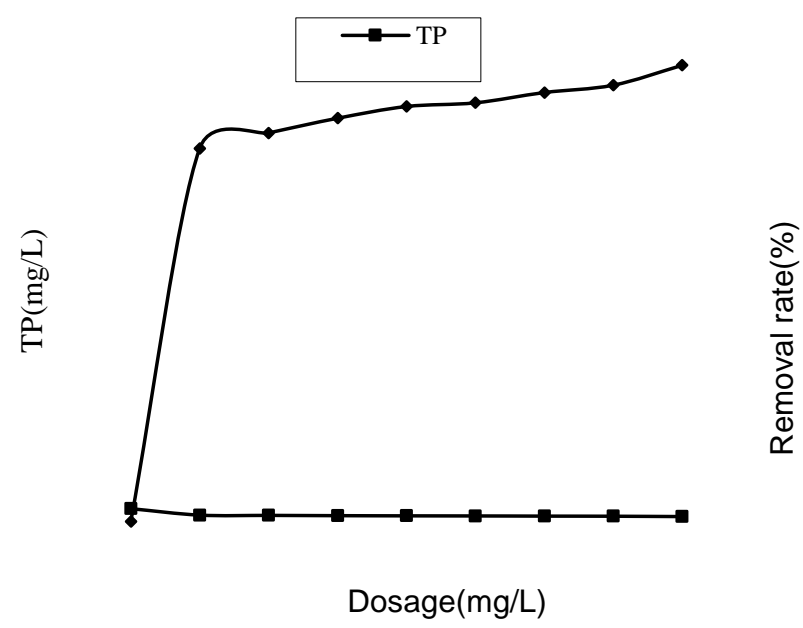

Figure 2. The effect of polyferric chloride dosage on TP removal of secondary effluent 
According to Figure 2, polymeric Fe showed similar TP removal rate as ionic $\mathrm{Fe}$. As its dosage increased in secondary effluent, the removal rate gradually grew. The difference was that polymeric Fe only had a little improvement of TP removal rate, from $50 \%$ to $62 \%$, when its dosage increased from $5 \mathrm{mg} / \mathrm{L}$ to $40 \mathrm{mg} / \mathrm{L}$. The TP concentration decreased from $1.74 \mathrm{mg} / \mathrm{L}$ to $0.66 \mathrm{mg} / \mathrm{L}$. The TP concentration in the polymeric Fe-treated supernatant did not reach the first level A criteria (TP $\leq 0.5 \mathrm{mg} / \mathrm{L}$ ) in the Discharge Standard of Pollutants for Municipal Wastewater Treatment Plant (GB18918-2002). Moreover, compared with the phosphorus removal pattern of ionic Fe, polymeric Fe reduced TP concentration in a relatively gentle way. Its amount in the supernatant had a downward linear correlation with TP concentration, but the slope was only about 0.14 . This indicated that ionic $\mathrm{Fe}$ was better at removing phosphorus than polymerized $\mathrm{FeCl}_{3}$.

\subsection{Phosphorus removal effect of gel Fe (ferric hydroxide)}

Figure 3 shows the TP removal effect of gel $\mathrm{Fe}$ in the secondary effluent, with dosages of $0 \mathrm{mg} / \mathrm{L}, 5 \mathrm{mg} / \mathrm{L}, 10$ $\mathrm{mg} / \mathrm{L}, 15 \mathrm{mg} / \mathrm{L}, 20 \mathrm{mg} / \mathrm{L}, 25 \mathrm{mg} / \mathrm{L}, 30 \mathrm{mg} / \mathrm{L}, 35 \mathrm{mg} / \mathrm{L}$ and 40 $\mathrm{mg} / \mathrm{L}$.

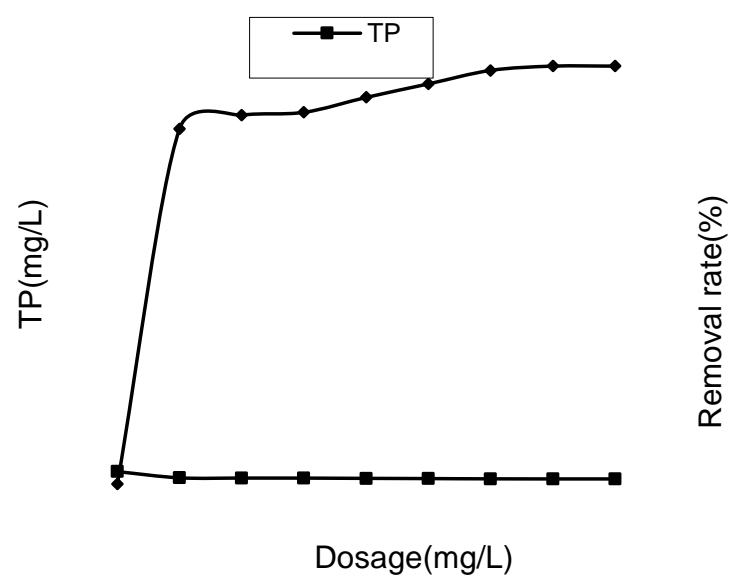

Figure 3. The effect of different dosages of ferric hydroxide on TP removal in the secondary effluent

According to Figure 3, gel Fe had similar phosphorus removal pattern as polymeric Fe. As the dosage of gel Fe increased, the TP removal rate in secondary effluent went up slowly. The difference was that when the dosage of gel Fe increased from $5 \mathrm{mg} / \mathrm{L}$ to $40 \mathrm{mg} / \mathrm{L}$, the TP removal rate grew from $50 \%$ to $59 \%$, and the TP concentration slightly dropped from $1.74 \mathrm{mg} / \mathrm{L}$ to $0.72 \mathrm{mg} / \mathrm{L}$. Thus, gel Fe had relatively lower ability to remove phosphorus than polymeric Fe. Its linear slope of correlation between dosage and removal rate was about 0.12 . The TP concentration in the supernatant treated by gel Fe failed to meet the level A criteria in the Discharge Standard of Pollutants for Municipal Wastewater Treatment Plant (GB18918-2002).

Based on our analysis and comparison, all forms of ferric salt, including ionic Fe, polymeric $\mathrm{Fe}$ and gel $\mathrm{Fe}$, have the ability to effectively remove phosphorus, but with different removal rates. To be specific, ionic Fe had the best effect on phosphorus removal. Its removal rate was $17 \%$ and $22 \%$ higher than those of polymeric Fe and gel Fe. Polymeric Fe was better at removing phosphorus than gel Fe, but its removal rate was only 5\% higher (Haroon et al., 2018; Ogunyele et al., 2018). This indicates that TP removal is mainly caused by ionic reaction of ferric salt coagulant and supplemented by polymeric adsorption. The degree of polymerization, or DP, has little effect on the removal process.

\section{Conclusions}

(1) When ionic Fe, polymeric Fe and gel Fe were used to remove phosphorus from the secondary effluent, all their TP removal rates increased with dosages. Among them, ionic Fe showed the best effect. When three $40 \mathrm{mg} / \mathrm{L}$ dosages of ionic $\mathrm{Fe}$, polymeric $\mathrm{Fe}$ and gel Fe were added into the secondary effluent, the phosphorus removal rates were $90 \%, 62 \%$ and $59 \%$, respectively. However, under such dosage, only ionic Fe could have higher than A-level performance that met the criteria of the Discharge Standard of Pollutants for Municipal Wastewater Treatment Plant (GB18918-2002). The other two forms of ferric salt failed to achieve the standard.

(2) When ferric salt dissolves in water, Fe ion will undergo hydrolysis and polymerization process, changing from ionic state to various hydroxyl complex forms. When the ionic Fe is added to the sewage, it reacts with the dissolved phosphate when hydrolyzed. This reaction plays an important role phosphorus removal process, as can be shown in the experimental results. When polymeric Fe or gel Fe are added to the sewage, they mainly remove gel $\mathrm{PO}_{4}{ }^{3-}$ by charge neutralization, adsorption bridging and floc scrolling. As these processes have relatively modest removal effect, they play a supplementary role in phosphorus removal.

(3) In practice, phosphorous removal projects should choose ionic Fe as absorbent for phosphate removal. However, as ionic $\mathrm{Fe}$ is a strong acid $(\mathrm{pH}<1)$, it will consume a certain alkalinity during phosphorus removal. Therefore, when the ionic Fe is used in the wastewater treatment plant to remove phosphorus from the influent, alkalinity should be appropriately added to facilitate nitrification in the subsequent biological denitrification to guanrantee the effects of biological denitrification.

(4) The experiment also shows that polymeric Fe and gel Fe at low dosage has better removal efficiency than ionic Fe. This is caused by two forms of phosphorus in the sewage - dissolved phosphorus and fine insoluble phosphorus. When dosages are kept low, ionic Fe can only react with dissolved phosphorus to form fine and insoluble ferric phosphate, which has poor settling ability. By contrast, polymeric $\mathrm{Fe}$ and gel $\mathrm{Fe}$ have better efficiency in phosphorus flocculation and sedimentation, for exsisting small and insoluble ones in particular (Amina and Kamel, 2019; Asadullah et al., 2018; Youdeowei et al., 2019). Therefore, low dosages of polymeric Fe and gel Fe greatly contribute to phosphorus removal and the reasons are yet to be studied and verified. 


\section{References}

Amina A. and Kamel K. (2019), Water quality of the Kebir Watershed, Northeast of Algeria, Journal Clean Was, 3, 28-32.

Asadullah N., Faizan A. and Farva K. (2018), Evaluation of low cost environment friendly natural extracts for the purification of drinking water, Earth Sciences Pakistan, 2, 23-25.

Chen Y.G., Randall A.A. and McCue T. (2004), The eficiency of enhanced biological phosphorus removal from real wastewater affected by diferent ratio of acetic to propionic acid, Water Research, 38, 27-36.

Deng R.S. and Guo J. (2002), A study on mechanism of biological denitrification and phosphorus removal for urban wastewater, Journal of Chongqing Jianzhu University, 24, 106-111.

Haroon R., Arslan C. and Shahbaz N.K. (2018), Wastewater irrigation, its impact on environment and health risk assessment in Peri urban areas of Punjab Pakistan - A review, Environmental Contaminants Reviews, 1, 30-35.

Hosseini S.A. and Sharifi F. (2019), Improvement stability of earth canal banks using geo-technical approaches, Geology, Ecology, and Landscapes, 3, 308-317, DOI: 10.1080/24749508.2018.1563751.

Hu Z.Y. and Ouyang X. (2006), Studies on removal of N and P in eutrophic water bodies, China Municipal Engineering, 123, 39-41.

Islam M.A., Islam S.M.A. and Sathi M.A. (2020), Identification of lentil varieties/lines resistant to stemphylium blight considering disease reaction and yield, Malaysian Journal of Sustainable Agriculture, 4, 22-25.

Jian F.L., Yang X.S. and Liang J.J. (2008), Phosphorus removal from municipal wastewater with filter materials, Ecology and Environment, 17, 55-58.

Jin X.B., Yu Y.M. and Zhang Y.F. (2002), Comparison between biol ogieal and chemieobiol ogieal phosphorus removal, Journal of Shanghai Teachers University (Natural Sciences), 31, 78-82.

Kang X.D. and Yang K. (2008), The comparative test of chemical phosphorous removal agent, Shanxi Architecture, 34, 194-195.

Liu H.L., Zhao X., Jiao R.Y., et al. (2011), Effects of polymer aluminum hydrolysis on phosphorus distribution in coagulation, Environmental Science, 32, 102-107.

Liu Y., Chen Y.G., Zhou Q., et al. (2007), Effect of initial pH control on biological phosphorus removal from wastewater containing acetic and pmpionic acids, Chemosphere, 66, 123-129.

Liu Z.P., Lu S.M. and Li S. (2003), The study on iron salt synchronization dephosphorization, Techniques and Equipment for Environmental Pollution Control, 4, 16-18.

Luo B., Liu S.Q. and Jiang Z.M. (2010), Study progress of domestic sewage dephosphorization technics, Journal of Anhui Agricultural Sciences, 38, 4769-4771, 4774.

Niu Y.H. (2006), Analysis of advantages and disadvantages of dephosphorization methods in wastewater treatment, Hebei Journal of Industrial Science and Technology, 358, 356-359.

Ogunyele A.C., Obaje S.O. and Akingboye A.S. (2018), Lithostructural relationships and petrogenetic affinities of the basement complex rocks around Okpella, Southwestern Nigeria, Earth Sciences Malaysia, 2, 29-36.

Parfitt R.L., Atkinson R.J., Smart R.St.C. (1975), The mechanism of phosphate fixation by iron oxides, Soil Science Society of America Journal, 39, 837-841.
Peng J.X. and Chen H.J. (1988), Nutrient Runoffs and Prevention, Beijing, China Environmental Science Press.

Tian S.Y. (1996), The effects of short chain fattyacidon biological phosphat release and PHB synthesis under anaerobic condition, Transactions of Tianjin University, 2, 87-91.

Wang H., An X. and Zhang Z. (2018), Effect of advanced treatment on ammonia nitrogen contained in secondary effluent from wastewater treatment plant, Fresenius Environmental Bulletin, 27, 2043-2050.

Wang K., Li L., Xue W., et al. (2017), Electrodeposition synthesis of pani/MNO2/graphene composite materials and its electrochemical performance, International Journal of Electrochemical Science, 12, 8306-8314.

Wang X.L. and Peng Y.Z. (2009), A2/O method wastewater biological nitrogen phosphorus. processing technology and application, Science Press.

Wu X.W., Li R.X., Xu Z.J., et al. (2010), Mesocosm experiments of nutrient effects on enteromorpha prolifera growth, Advances in Marine Science, 10, 538-544.

Xiong G.X., Luo J.Z. and Feng A.K. (2006), The removal of phosphorus from wastewater and the research trends, Industrial Safety and Environmental Protection, 32, 19-21.

Yang A., Han Y., Li S., et al. (2017), Synthesis and comparison of photocatalytic properties for bi2wo6 nanofibers and hierarchical microspheres, Journal of Alloys and Compounds, 695, 915-921.

Yang Y.L., Li X. and Fan Q. (2009), Preparation of iron-aluminum composited adsorbent and the removal trace phosphorus, Transactions of Beijing Institute of Technology, 29, 73-75.

Youdeowei P.O., Nwankwoala H.O. and Desai D.D. (2019), Dam structures and types in nigeria: sustainability and effectiveness, Water Conservation and Management, 3, 20-26.

Zhang J.Q. and Peng Y.Z. (2011), Effect of COD on enhanced biological phosphorus removal system and variation of OUR, Chinese Journal of Environmental Engineering, 5, 301-305.

Zhang L., Chen J., Zhang L., et al. (2019), Preparation of soybean oil factory sludge catalyst and its application in selective catalytic oxidation denitration process, Journal of Cleaner Production, 225, 220-226.

Zhang L., Jia Y., Zhang L., et al. (2019), Preparation of soybean oil factory sludge catalyst by plasma and the kinetics of selective catalytic oxidation denitrification reaction, Journal of Cleaner Production, 217, 317-323.

Zulkapli M.F., Rashid N.M., Mohd Nazri M.S. and Noorshawal N. (2018), Study on optical properties of graphene-Tio 2 nanocomposite as photoanodes layer in dye sensitized solar cell (DSSC), Environment \& Ecosystem Science, 2, 39-41. 